\section{Repeat abortion in Britain}

I read with interest the article on repeat abortion $^{1}$ by Stone and Ingham in the October 2011 issue of the Journal that explores the characteristics of women who underwent repeat termination of pregnancy (TOP) in England and Wales in 2010-2011. The article's findings closely match those of a study ${ }^{2}$ I performed 30 years ago in Bristol, which had the identical objective. Our study was of a similar size: 799 women undergoing TOP, of whom 160 (16.7\%) were having a repeat TOP.

I mention this study for four reasons. First, because it was published in this Journal before it changed its name. Second, I doubt the authors would have found the article because the Journal was not cited at that time - accessing such articles can be difficult, but can be beneficial to studying trends over time, for example. Third, we found similar risk factors for repeat TOP: young age (not surprisingly), belonging to non-white ethnic group, deprivation (in our case low social class) and poor contraceptive use (declined contraception after first TOP and no formal follow-up). Fourth, I would sadly conclude that despite the advance in the range of contraceptive methods available, 30 years later it is still the same vulnerable groups that suffer repeat TOP with its attendant physical, social and psychological consequences.

It appears that family planning services need to try harder to reach such groups and meet their contraceptive and belief needs. Some policy initiatives - such as making emergency contraception available to buy over the counter - will differentially benefit those that can easily pay who are unlikely to be in the at-risk groups identified by both studies.

Lindsay Smith, MD, PhD

General Practitioner, West Coker, Somerset, UK: Ifpsmith@globalnet.co.uk

Competing interests None.

J Fam Plann Reprod Health Care 2012;38:66.

doi:10.1136/jprhc-2011-100237

\section{REFERENCES}

1. Stone N, Ingham R. Who presents more than once? Repeat abortion among women in Britain. J Fam Plann Reprod Health Care 2011;37:209-215.
Smith LFP, Pimm MH, Hull MG, et al. Identifying women undergoing termination of pregnancy who are likely to return for another. Br J Fam Plann 1983;9:45-49. 